\title{
Determining the Quality of Educational Climate in a Private Medical College in Bangladesh via the ‘Dundee Ready Education Environment Measure' Instrument
}

\author{
Masuda Mohsena' ${ }^{1}$, Smita Debsarma ${ }^{2}$, Mainul Haque ${ }^{3 *}$ \\ 'Department of Community Medicine, Ibrahim Medical College, Shahbagh, Dhaka 1000, Bangladesh. \\ 2Department of Community Medicine, Ibrahim Medical College, Shahbagh, Dhaka 1000, Bangladesh. \\ 'Unit of Pharmacology, Faculty of Medicine and Defense Health, National Defence University of Malaysia, Kem Sungai Besi, 57000 Kuala Lumpur, Malaysia.
}

\begin{abstract}
Background: The educational environment is an important determining factor of an effective curriculum. An enriched learning environment can lead to increased satisfaction, achievement and success as a practitioner. The educational environment has been defined as "environment experienced or perceived by the students as well as by the teachers." Learning environment research seeks to assess the students' perceptions of their environment and can guide medical teachers to introspect, devise, and incorporate the best learning strategy for the improvement of the educational environment. The recent concern to enhance quality assessment procedures in the health professions, and institutions have led to renewed interest in students' perceptions of the educational environment. The aim of this study is to evaluate, by way of students' perceptions, the overall education environment, as well as, other aspects of the educational environment of Ibrahim Medical College, Bangladesh. Methods: This crosssectional survey was conducted among the medical students in the year 2015, who were enrolled in the undergraduate MBBS program. DREEM questionnaire was used for data collection. The data was later regrouped according to the five domains. SPSS, IBM 20 has been used for data analysis. Results: Among the 416 student participants, 277 were female $(67 \%)$, and 139 were male $(33 \%)$. Comparison of the mean scores of pooled total and 4 sub-scales revealed no significant difference between genders, whereas in Students' Academic Self-Perceptions scale average rating for a male was found statistically significantly higher $(p<0.05)$. Conclusion: This study suggests that students, in general, hold positive perceptions of their course environment. These results can serve as a baseline for a longitudinal quality assessment of pupils' perceptions of the college.
\end{abstract}

Key word: Quality, Private Medical College, Bangladesh, DREEM.

\section{PICTORIAL ABSTRACT}

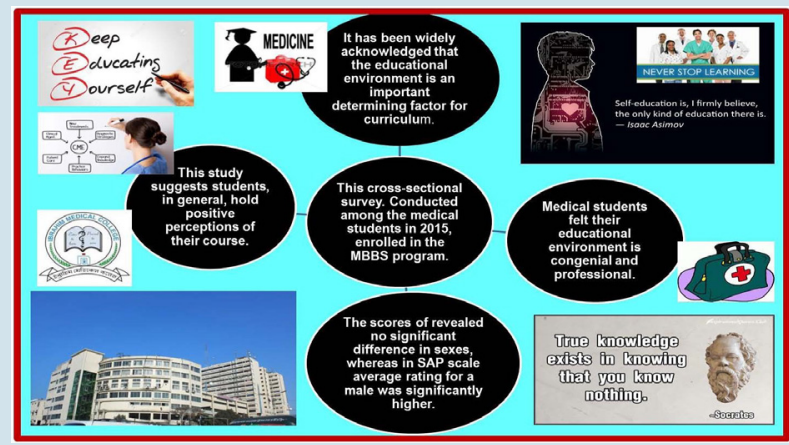

Correspondence :

Mainul Haque

Professor and Head of the Unit of Pharmacology, Faculty of Medicine and Defense Health, National Defence University of Malaysia, Kem Sungai Besi, 57000 Kuala Lumpur, Malaysia.

Cell Phone: + 60109265543

E-mail: runurono@gmail.com

DOI: 10.5530/jyp.2016.3.17

\section{INTRODUCTION}

"Providing quality education is the priority of the most of the countries". Therefore, it has been widely acknowledged that the educational environment is an important determining factor of an effective curriculum as there is a strong association between teaching and learning. ${ }^{2,3}$ The UK Standing Committee on Postgraduate Education highlighted the importance of educational environment in their statement report, in which an environment that is conducive has a positive and significant impact on students' learning, academic progress, and well-being. ${ }^{4}$ It is also accepted that a positive learning environment during undergraduate education can lead to increased satisfaction, achievement and success as a practitioner. ${ }^{5,6}$ The educational environment has been defined as "environment experienced or perceived by the students as well as by the teachers". These perceptions would be based on three important aspects which include: the physical environment, emotional climate, and intellectual climate. ${ }^{8}$ As educational institutes continue to become more student oriented, students' perceptions of higher educational facilities and services are becoming increasingly important. ${ }^{7}$ Learning environment research seeks to assess the students' perceptions of their environment and can guide medical teachers to introspect, devise, and incorporate

the best learning strategy for the improvement of the educational environment. ${ }^{9}$ The recent concern to enhance quality assessment procedures in the health professions, institutions have led to a renewed interest in students' perceptions of the educational environment. ${ }^{10}$

In order for educationalists to provide the highest quality of teaching to their pupils, it is a prerequisite to create an environment favorable to learning. This improvement can be achieved by identifying the weaknesses in the environment. ${ }^{7}$ Students' perception of the educational environment is a useful basis for modifying and improving its quality. To measure medical and health education environment, the Dundee Ready Education, Environment Measure (DREEM) was developed. ${ }^{11,12}$ DREEM was tested in Europe, Africa, Asia, Australia and America. ${ }^{13}$ It has been shown to be independent of culture, and has been translated in to various languages and used in many countries. ${ }^{14,15}$ In accordance to DREEM questionnaire, students' perception on educational environment items were subdivided into 5 sub-scales which are explained in the method section. The sub-scales give the opportunity to the researcher to specify weaknesses or strengths of the whole program. However, it is clear that such questionnaires cannot reveal the whole story. While they may be valuable in identifying areas of concern shared by a majority 
of students, they yield no insight into the underlying reasons for these responses. ${ }^{16}$ The aim of this study was to evaluate, by way of students' perceptions, the overall education environment, as well as, other aspects of the educational environment of Ibrahim Medical College (IMC), Shahbagh, Dhaka 1000, Bangladesh. The second aim of this study was to investigate whether the perception of educational environment or aspects of it was different, by students of different year levels or gender.

\section{MATERIALS AND METHODS}

This cross-sectional survey was conducted among the medical students in the year 2015, who were enrolled in the undergraduate MBBS program (first to the fifth year) at IMC, which is one of the most renowned private medical colleges in Bangladesh. The curriculum in this college and all other medical schools, including public and private are based on an approved document by the Bangladesh Medical and Dental Council (BMDC). Preclinical subjects (Anatomy, Physiology, and Biochemistry) were taught in the first three terms; students in term four to seven study para-clinical subjects (Community Medicine, Forensic Medicine, Pathology, Microbiology and Pharmacology) and had exposures to Medicine, Surgery, Gynecology and in the rest of the three terms, students were exposed to all clinical subjects. The College has started in the year 2000, and $10^{\text {th }}$ to $14^{\text {th }}$ batches were studying in $10^{\text {th }}, 8^{\text {th }}, 6^{\text {th }}, 4^{\text {th }}$ and $2^{\text {nd }}$ terms, respectively during the period of the study.

Internationally validated English version of the DREEM questionnaire was used for data collection. DREEM consists of a 50 item inventory (Table 4); each of the 50 items is scored on a 5 -point scale, where $4=$ Strongly agree, $3=$ Agree, $2=$ Unsure, $1=$ Disagree and $0=$ Strongly disagree. Reverse scoring is required for items 4, 8, 9, 17, 25, 35, 39, 48 and 50 (individual items are detailed in Table 4). Thus, higher scores indicate a more positive evaluation. ${ }^{10}$ The 50 -item DREEM has a maximum score of 200 indicating the ideal educational environment as perceived by the students. A score of 0 is the minimum and would be a deeply worrying result for any medical educator and warrant intervention. The approximate guide to interpreting the overall score is 0-50: Very Poor, 51-100: Plenty of Problems, and 101-150: More Positive than Negative, 151-200: Excellent. ${ }^{17}$ Items that have a mean score of 3.5 or more are real positive points. Any item with a mean of 2 or less should be examined more closely as they indicate problem areas. Items with a mean between 2 and 3 are aspects of the climate that could be enhanced. ${ }^{17}$

As well as the total DREEM score, the data was later regrouped according to the five domains, as questions about perception were in different locations in the original questionnaire. These domains are: Students' Perceptions of Learning (SPL), Students' Perceptions of Teachers (SPT), Students' Academic Self-perceptions (SAP), Students' Perceptions of Academic Atmosphere (SPA) and Students' Social Self-perceptions (SSP). The subscales are then interpreted with the cutoff point. ${ }^{17}$ (Table 3). A short demographic questionnaire was included to collect information such as the participant's gender, religion, age group, accommodation, the previous medium of education and CGPAs.
This study obtained ethical approval from the Institutional Review Board and Ethics Committee of the Ibrahim Medical College, Shahbag, Dhaka 1000 , Bangladesh. Informed written consent was obtained from the participants to utilize their data for research purposes. The questionnaires were handed over to all students present in the class (each year separately) during a routine lecture, in September to October 2015. Before administering the questionnaire, the students were made aware of the purpose of the study. Participation was voluntary, and the returned questionnaires were anonymous. Some terms, such as ridicule, authoritarian, etc. were explained to the students before they filled up the questionnaire. Among the 538 college students studying in that period, 440 participated in this study, representing a response rate of $82 \%$. Returned questionnaires having a missing value in any of the variables were excluded from the analysis. Fully completed responses from of 416 participants was finally used for analysis, so the ultimate response rate was $77 \%$ (Table 1 and Figure 1). For data analysis, SPSS, IBM 20 has been used. A descriptive analysis of the collected data was done in the form of frequencies and mean $\pm \mathrm{SD}$. Student's t-test or Analysis of Variance (ANOVA) with post-hoc tests were used to compare the means between different groups. $\mathrm{P} \leq 0.05$ was chosen as the level of statistical significance.

\section{RESULTS}

Among the 416 student participants, 277 were female (67\%), and 139 were male $(33 \%)$. The age range was 18 to 26 with a mean $( \pm$ SD) of $21.7( \pm 1.6)$. Above $90 \%$ of them were Muslims and previous medium of instruction of $96 \%$ was Bangla (Table 2 and Figure 2). The mean of total and five sub-scales were categorized on the four tiered scale (Table 3 and Figure 3). The average total score achieved by the students was 123.6. The majority $(76.9 \%)$ of the students responded 'more positively than negatively' to DREEM inventory. 'A more positive perception' was observed among $76.4 \%$ students in the domain of SPL. In SPT domain, $72.1 \%$ perceived that teachers were 'moving in the right direction. The majority (66.6\%) also had an academic self-perception that was 'more on the positive side. Faculty atmosphere was perceived as 'a more positive atmosphere' by $61.8 \%$, while $23.1 \%$ thought that there were issues that need changing. Nearly $65 \%$ thought that the society they live in was 'not too bad' while nearly one-third believed their society was 'not a nice place to be.' Students' social self-perception obtained the lowest $(16.1 \pm 3.7)$ mean scores among the sub-scales (Table 3). Overall, a level 3 score on all five sub-scales were found; the five sub-scales scores were a step below the ideal of the four tiered scale (Table 3 ).

Nine of individual domains in pooled data with male and female comparison shows that item 2 (teachers are knowledgeable) had the highest score of 3.5 indicating a positive aspect of the SPT domain (Table 4). Well prepared teachers in class and their good communication skills with patients, encourages medical students to participate in class, learning empathy and having good friends in college were identified as the positive environment (mean scores above 3 ) in the college (Table 4). Whereas, eight items scored below 2 and two of these were even $\leq 1.5$ (item 9 and 25)

Table 1: Batch-wise response rate to DREEM questionnaire for students of IMC (The year 2015)

\begin{tabular}{|c|c|c|c|}
\hline Batches & $\begin{array}{c}\text { Total Students In } \\
\text { The Batch (A) }\end{array}$ & $\begin{array}{c}\text { Students Present In } \\
\text { Class (B) n (\%=B/A*100) }\end{array}$ & $\begin{array}{l}\text { The Students Who Responded } \\
\text { To Complete Questionnaires } \\
\text { (C) and (\%=C/B*100) }\end{array}$ \\
\hline $10^{\text {th }}$ batch $($ Term 10$)$ & 102 & $92(90)$ & $85(92)$ \\
\hline $11^{\text {th }}$ batch $($ Term 8$)$ & 107 & $85(79)$ & $80(94)$ \\
\hline $12^{\text {th }}$ batch (Term 6) & 113 & $87(77)$ & $82(94)$ \\
\hline $13^{\text {th }}$ batch $($ Term 4$)$ & 107 & $86(80)$ & $80(93)$ \\
\hline $14^{\text {th }}$ batch $($ Term 2$)$ & 109 & $90(83)$ & 89 (99) \\
\hline Total & 538 & $440(82)$ & $416(95)$ \\
\hline
\end{tabular}

Response rate $=416 / 538^{\star} 100=77 \%$. 


\begin{tabular}{cccc} 
Table 2: Demographic information about the students & $(\mathbf{n}=\mathbf{4 1 6})$ & \\
\hline Variable & Category & $\mathbf{n}$ & $\%$ \\
\hline \multirow{2}{*}{ Gender } & Male & 139 & 33.4 \\
& Female & 277 & 66.6 \\
Age & $<20$ & 108 & 26.0 \\
& $21-22$ & 163 & 39.2 \\
& $\geq 23$ & 145 & 34.9 \\
& 10 (Term-10) & 85 & 20.4 \\
IMC Batches & 11 (Term-8) & 80 & 19.2 \\
& $12($ Term 6) & 82 & 19.7 \\
& 13 (Term 4) & 80 & 19.2 \\
Previous educational Medium & 14 (Term 2) & 89 & 21.4 \\
& Bangla & 398 & 95.7 \\
Accommodation & English & 18 & 4.3 \\
& Hostel \& others & 130 & 31.3 \\
& Home & 286 & 68.8 \\
& Islam & 378 & 90.9 \\
Religion & Hinduism & 37 & 8.9 \\
& Others & 1 & 0.2 \\
\hline
\end{tabular}

Table 3: Description of The Five Domains of The Educational Environment as Reported by the Students of Ibrahim Medical College during the Academic Year 2015

\begin{tabular}{|c|c|c|c|}
\hline $\begin{array}{c}\text { Domain } \\
\text { (Maximum Score) }\end{array}$ & $\begin{array}{c}\text { Sample } \\
\text { Mean }( \pm S D)\end{array}$ & Interpretation [15] & $\mathrm{N}(\%)$ \\
\hline Total & 123.6 & Very Poor $(0-50)$ & $0(0)$ \\
\hline \multirow[t]{3}{*}{ (Max score 200) } & $( \pm 20.9)$ & Plenty of Problems (51-100) & $57(13.7)$ \\
\hline & & More Positive than Negative (101-150) & $320(76.9)$ \\
\hline & & Excellent (151-200) & $39(9.4)$ \\
\hline \multirow{4}{*}{$\begin{array}{l}\text { Students' Perception of Learning } \\
\text { (SPL) (max score } 48)\end{array}$} & 30.3 & Very poor $(0-12)$ & $1(0.2)$ \\
\hline & $( \pm 5.3)$ & Teaching is viewed negatively (13-24) & $56(13.5)$ \\
\hline & & A more positive approach (25-36) & $318(76.4)$ \\
\hline & & Teaching highly thought of (37-48) & $41(9.9)$ \\
\hline Students' Perception of Teachers & 28.3 & Abysmal (0-11) & $0(0)$ \\
\hline \multirow[t]{3}{*}{ (SPT) (max score 44$)$} & $( \pm 4.9)$ & In need of some retraining (12-22) & $56(13.5)$ \\
\hline & & Moving in the right direction (23-33) & $300(72.1)$ \\
\hline & & Model teachers (34-44) & $60(14.4)$ \\
\hline Students' Academic Self-Perceptions & 20.1 & Feeling of total failure $(0-8)$ & $3(0.7)$ \\
\hline \multirow[t]{3}{*}{ (SAP) (max score 32) } & $( \pm 4.3)$ & Many negative aspects (9-16) & $75(18.0)$ \\
\hline & & Feeling more on the positive side (17-24) & $277(66.6)$ \\
\hline & & Confident (25-32) & $61(14.7)$ \\
\hline Students' Perception of Atmosphere & 29.1 & A terrible environment $(0-12)$ & $8(1.9)$ \\
\hline \multirow[t]{3}{*}{ (SPA) (max scores 48) } & $( \pm 7.1)$ & There are many issues that need changing (13-24) & $96(23.1)$ \\
\hline & & A more positive atmosphere (25-36) & $257(61.8)$ \\
\hline & & A good feeling overall (37-48) & $55(13.2)$ \\
\hline \multirow{4}{*}{$\begin{array}{l}\text { Students' Social Self-Perceptions } \\
\text { (SSP) (max score 28) }\end{array}$} & 16.1 & Miserable (0-7) & $7(1.7)$ \\
\hline & $( \pm 3.7)$ & Not a nice place (8-14) & $121(29.1)$ \\
\hline & & Not too bad (15-21) & $269(64.7)$ \\
\hline & & Very good socially (22-28) & $19(4.6)$ \\
\hline
\end{tabular}

indicating causes of concern. The students perceived emphasis over authentic learning and teacher-centered teaching as problem areas. Teachers' getting angry in the class was also documented negative. The students indicated that they preferred teachers to be less authoritarian. Not being able to memorize all they need is also a problem for them. In the sub-scale of students' perception of atmosphere, the students identified the environment as a stressful and less enjoyable one. The study group invariably agreed that they had problems with the support systems available for those who were stressed (Table 4).
Comparison of the mean scores of pooled total and 4 sub-scales (SPL, SPT, SPA and SSP) revealed no significant difference between male and female students, whereas in Students' Academic Self-Perceptions (SAP) scale average score for a male was found higher compared to that of females $(\mathrm{p}<0.05)$. In seven individual items, female students scored significantly lower than that of the male students (Table 4) i.e. Females felt less clear about the learning objectives, less confident about passing and less prepared for the future compared to male students. Teaching was not perceived sufficient to develop confidence and opportunities 


\begin{tabular}{|c|c|c|c|c|c|c|c|c|c|}
\hline & \multirow[t]{2}{*}{ Domain } & \multicolumn{2}{|c|}{$\begin{array}{c}\text { Total } \\
(n=416)\end{array}$} & \multicolumn{2}{|c|}{ Male $(n=139)$} & \multicolumn{2}{|c|}{ Female $(n=277)$} & \multirow[b]{2}{*}{$\mathrm{t}$} & \multirow[b]{2}{*}{$\mathrm{p}$} \\
\hline & & Mean & SD & Mean & SD & Mean & SD & & \\
\hline \multirow[t]{12}{*}{ I } & 1. I am encouraged to participate in class & 3.1 & 0.74 & 3.1 & 0.7 & 3.1 & 0.7 & 0.56 & ns \\
\hline & 7. The teaching is often stimulating & 2.7 & 0.82 & 2.7 & 0.8 & 2.7 & 0.8 & 0.27 & ns \\
\hline & 13. The teaching is student-centered & 2.6 & 0.95 & 2.6 & 1.0 & 2.6 & 0.9 & 0.31 & ns \\
\hline & 16. The teaching is sufficiently concerned to develop my competence & 2.8 & 0.90 & 2.8 & 0.9 & 2.7 & 0.9 & 0.55 & ns \\
\hline & 20. The teaching is well focused & 2.9 & 0.77 & 2.9 & 0.8 & 2.9 & 0.7 & 0.13 & ns \\
\hline & 22. The teaching is sufficiently concerned to develop my confidence & 2.5 & 0.99 & 2.6 & 1.0 & 2.4 & 1.0 & 2.27 & $<0.05$ \\
\hline & 24. The teaching time is put to good use & 2.7 & 0.80 & 2.7 & 0.8 & 2.7 & 0.8 & 0.62 & ns \\
\hline & 25. The teaching over-emphasized factual learning & 1.5 & 0.85 & 1.5 & 0.8 & 1.4 & 0.9 & 0.67 & ns \\
\hline & 38. I am clear about the learning objectives of the course & 2.7 & 0.86 & 2.8 & 0.9 & 2.7 & 0.8 & 1.99 & $<0.05$ \\
\hline & 44. The teaching encourages me to be an active learner & 2.6 & 1.00 & 2.6 & 1.0 & 2.5 & 1.0 & 1.37 & ns \\
\hline & 47. Long term learning is emphasized over the short term & 2.5 & 0.88 & 2.5 & 0.8 & 2.5 & 0.9 & 0.41 & ns \\
\hline & 48. The teaching is too teacher-centered & 1.9 & 1.04 & 2.0 & 1.1 & 1.9 & 1.0 & 1.00 & ns \\
\hline \multirow[t]{11}{*}{ II } & 2. The teachers are knowledgeable & 3.5 & 0.64 & 3.5 & 0.6 & 3.5 & 0.7 & 0.08 & ns \\
\hline & 6 . The teachers are patient with patients & 2.7 & 0.86 & 2.6 & 0.9 & 2.7 & 0.8 & 1.68 & ns \\
\hline & 8. The teachers ridicule the students & 2.1 & 1.11 & 2.1 & 1.1 & 2.1 & 1.1 & 0.81 & ns \\
\hline & 9. The teachers are authoritarian & 1.4 & 0.94 & 1.4 & 1.0 & 1.4 & 0.9 & 0.16 & ns \\
\hline & 18. The teachers have good communication skills with patients & 3.0 & 0.83 & 2.9 & 0.8 & 3.0 & 0.8 & 1.50 & ns \\
\hline & 29. The teachers are good at providing feedback to students & 2.7 & 0.93 & 2.7 & 0.9 & 2.7 & 0.9 & 0.44 & ns \\
\hline & 32. The teachers provide constructive criticism here & 2.3 & 1.07 & 2.3 & 1.1 & 2.2 & 1.1 & 0.45 & ns \\
\hline & 37. The teachers give clear examples & 2.9 & 0.82 & 2.9 & 0.8 & 2.9 & 0.8 & 0.26 & $\mathrm{~ns}$ \\
\hline & 39. The teachers get angry in class & 1.9 & 1.18 & 2.0 & 1.2 & 1.8 & 1.1 & 1.12 & ns \\
\hline & 40. The teachers are well prepared for their classes & 3.1 & 0.82 & 3.0 & 0.9 & 3.1 & 0.8 & 1.87 & ns \\
\hline & 50. The students irritate the teachers & 2.6 & 1.16 & 2.7 & 1.1 & 2.5 & 1.2 & 1.39 & ns \\
\hline \multirow[t]{8}{*}{ III } & $\begin{array}{l}\text { 5. Learning strategies which worked for me before continue to work for } \\
\text { me now }\end{array}$ & 2.3 & 1.00 & 2.4 & 1.0 & 2.2 & 1.0 & 1.24 & ns \\
\hline & 10. I am confident about passing this year & 2.7 & 0.92 & 2.9 & 0.9 & 2.6 & 0.9 & 3.54 & $<.0 .005$ \\
\hline & 21. I feel I am being well prepared for my profession & 2.6 & 0.86 & 2.8 & 0.9 & 2.5 & 0.8 & 2.83 & $<0.005$ \\
\hline & 26. Last year's work has been a good preparation for this year's work & 2.5 & 0.86 & 2.5 & 0.8 & 2.5 & 0.9 & 0.70 & ns \\
\hline & 27. I am able to memorize all I need & 1.8 & 1.05 & 1.8 & 1.0 & 1.8 & 1.1 & 0.42 & ns \\
\hline & 31. I have learned a lot about empathy in my profession & 3.0 & 0.80 & 3.1 & 0.7 & 2.9 & 0.8 & 1.60 & ns \\
\hline & 41. My problem-solving skills are being well developed here & 2.5 & 0.95 & 2.5 & 0.9 & 2.4 & 1.0 & 1.08 & ns \\
\hline & 45. Much of what I have to learn seems relevant to a career in medicine & 2.8 & 0.78 & 2.8 & 0.7 & 2.8 & 0.8 & 0.19 & ns \\
\hline \multirow[t]{12}{*}{ IV } & 11. The atmosphere is relaxed during the ward teaching & 2.0 & 1.07 & 2.1 & 1.1 & 1.9 & 1.1 & 1.43 & ns \\
\hline & 12. This school is well timetabled & 2.8 & 1.08 & 2.9 & 1.1 & 2.8 & 1.1 & 0.26 & ns \\
\hline & 17. Cheating is a problem in this school & 2.5 & 1.28 & 2.7 & 1.2 & 2.4 & 1.3 & 2.10 & $<0.05$ \\
\hline & 23. The atmosphere is relaxed during lectures & 2.5 & 1.08 & 2.5 & 1.1 & 2.6 & 1.1 & 0.56 & ns \\
\hline & 30. There are opportunities for me to develop interpersonal skills & 2.4 & 1.08 & 2.7 & 1.0 & 2.3 & 1.1 & 3.40 & $<0.005$ \\
\hline & 33. I feel comfortable in the class socially & 2.7 & 0.94 & 2.8 & 0.9 & 2.7 & 1.0 & 1.34 & ns \\
\hline & 34. The atmosphere is relaxed during seminars /tutorials & 2.7 & 0.98 & 2.6 & 1.0 & 2.7 & 1.0 & 0.62 & ns \\
\hline & 35. I find the experience disappointing & 2.2 & 1.06 & 2.1 & 1.2 & 2.2 & 1.0 & 0.66 & ns \\
\hline & 36. I am able to concentrate well & 2.3 & 1.02 & 2.5 & 1.0 & 2.3 & 1.0 & 2.09 & $<0.05$ \\
\hline & 42. The enjoyment outweighs the stress of studying medicine & 2.1 & 1.16 & 2.2 & 1.1 & 2.0 & 1.2 & 1.62 & ns \\
\hline & 43. The atmosphere motivates me as a learner & 2.4 & 1.02 & 2.5 & 1.0 & 2.4 & 1.0 & 1.27 & ns \\
\hline & 49. I feel able to ask the questions I want & 2.5 & 1.06 & 2.6 & 1.0 & 2.5 & 1.1 & 0.93 & ns \\
\hline \multirow[t]{7}{*}{$\mathrm{V}$} & 3. There is a good support system for students who get stressed & 1.6 & 1.17 & 1.7 & 1.2 & 1.6 & 1.2 & 0.87 & ns \\
\hline & 4. I am too tired to enjoy this course & 1.8 & 1.15 & 1.9 & 1.2 & 1.7 & 1.1 & 1.40 & ns \\
\hline & 14. I am rarely bored on this course & 1.8 & 1.18 & 1.8 & 1.2 & 1.8 & 1.2 & 0.15 & ns \\
\hline & 15. I have good friends in the school & 3.1 & 1.01 & 3.1 & 0.9 & 3.1 & 1.0 & 0.34 & ns \\
\hline & 19. My social life is good & 2.9 & 0.97 & 2.9 & 1.0 & 2.9 & 1.0 & 0.47 & ns \\
\hline & 28. I seldom feel lonely & 2.1 & 1.27 & 2.2 & 1.2 & 2.1 & 1.3 & 0.87 & ns \\
\hline & 46. My accommodation is pleasant & 2.7 & 1.13 & 2.7 & 1.1 & 2.7 & 1.1 & 0.51 & ns \\
\hline
\end{tabular}


Table 5: Average DREEM Scores (Total And Sub-Scales) for Comparison among Five Different Batches of Students Of Ibrahim Medical College, Bangladesh in the Year 2015

\begin{tabular}{|c|c|c|c|c|c|c|c|}
\hline & Domain & $10^{\text {th }}$ batch & $11^{\text {th }}$ batch* & $12^{\text {th }}$ batch & $13^{\text {th }}$ batch & $14^{\text {th }}$ batch & $\begin{array}{l}\text { Mean difference is significant } \\
\text { (reference } 10^{\text {th }} \text { batch) }\end{array}$ \\
\hline \multirow{2}{*}{ I } & \multirow{2}{*}{ Students' perception of learning } & 30.0 & 27.1 & 32.8 & 31.4 & 30.3 & 10 vs $11: \mathrm{p}<0.005$ \\
\hline & & $(5.3)$ & $(4.7)$ & $(4.8)$ & $(4.8)$ & $(5.4)$ & 10 vs $12: \mathrm{p}<0.005$ \\
\hline \multirow{2}{*}{ II } & \multirow{2}{*}{ Students' perception of teachers } & 28.1 & 25.4 & 30.0 & 31.4 & 26.7 & 10 vs $11: \mathrm{p}<0.002$ \\
\hline & & $(4.7)$ & $(4.0)$ & $(3.9)$ & $(4.0)$ & $(5.1)$ & 10 vs $13: p<0.001$ \\
\hline \multirow{2}{*}{ III } & \multirow{2}{*}{ Students' academic self-perception } & 20.8 & 18.7 & 21.3 & 20.9 & 18.9 & 10 vs $11: \mathrm{p}<0.02$ \\
\hline & & $(4.0)$ & $(4.8)$ & $(4.0)$ & $(4.0)$ & (3.8) & 10 vs $14: \mathrm{p}<0.05$ \\
\hline \multirow{2}{*}{ IV } & \multirow{2}{*}{ Students' perception of atmosphere } & 29.4 & 24.8 & 30.8 & 30.6 & 29.7 & 10 vs $11: p<0.001$ \\
\hline & & $(6.7)$ & (6.3) & $(7.4)$ & $(6.9)$ & $(6.4)$ & \\
\hline \multirow{4}{*}{$\mathrm{V}$} & \multirow{2}{*}{ Students' social self -perception } & 15.4 & 14.8 & 16.7 & 16.7 & 16.7 & \\
\hline & & (3.6) & $(3.2)$ & $(4.0)$ & (3.6) & (3.8) & \\
\hline & \multirow{2}{*}{ Total } & 123.29 & 110.36 & 131.55 & 130.93 & 121.89 & 10 vs $11: p<0.001$ \\
\hline & & $(20.22)$ & $(18.29)$ & $(19.99)$ & $(18.92)$ & $(20.20)$ & \\
\hline
\end{tabular}

${ }^{*}$ post hoc test reveals that the mean values of $11^{\text {th }}$ batch are significantly lower in most of these domains compared to other batches.

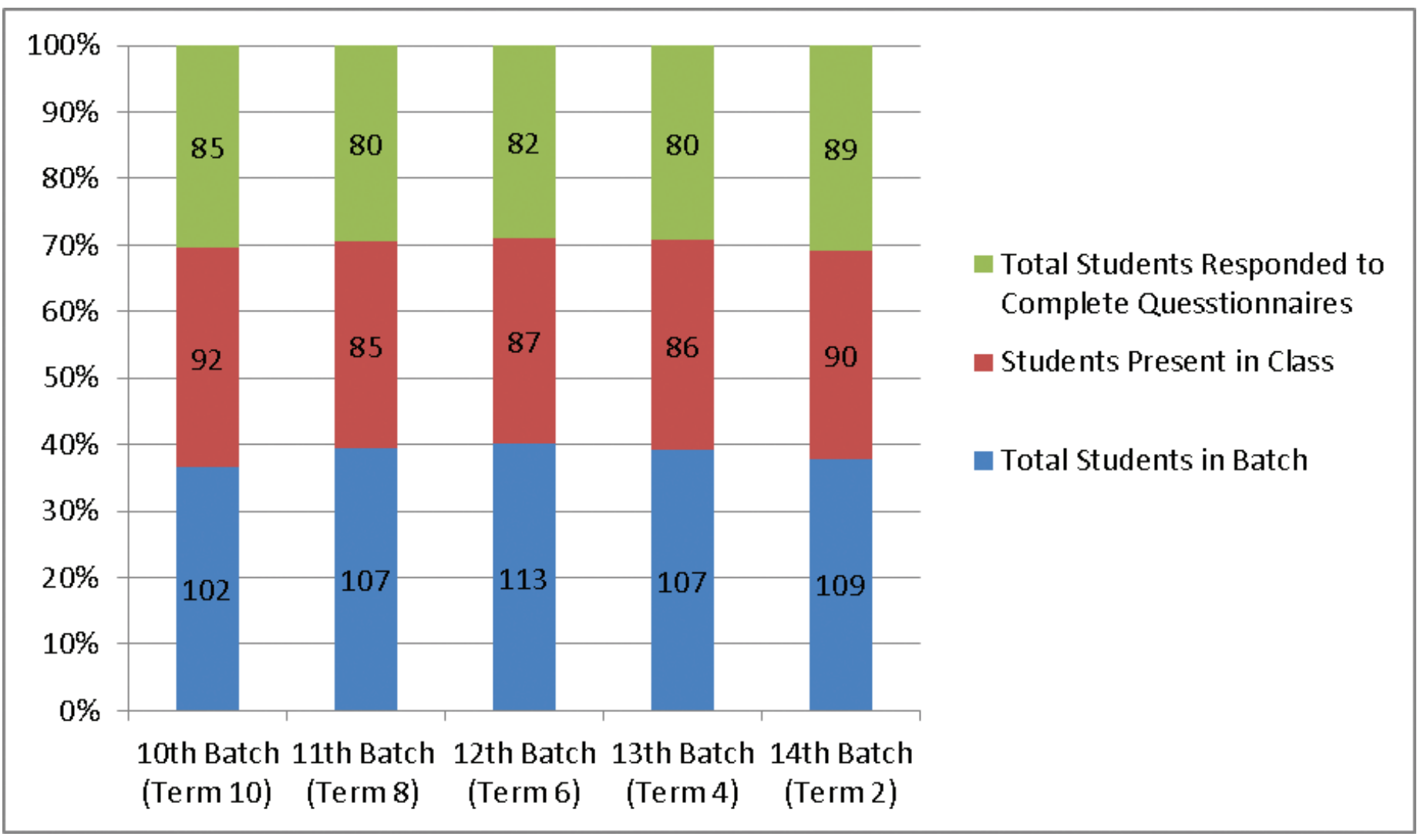

Figure 1: Batch-wise response rate to DREEM questionnaire for students of IMC (The year 2015) (Response rate=77\%). 

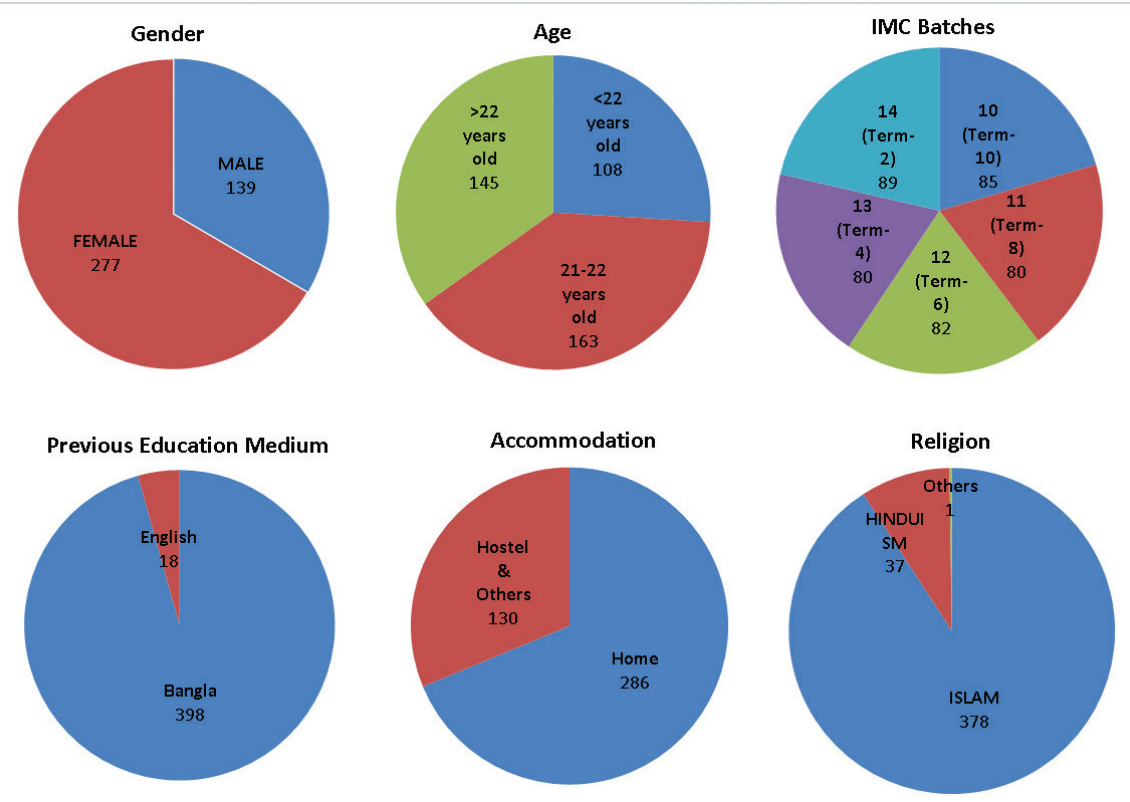

Figure 2: Demographic information about the students $(n=416)$.

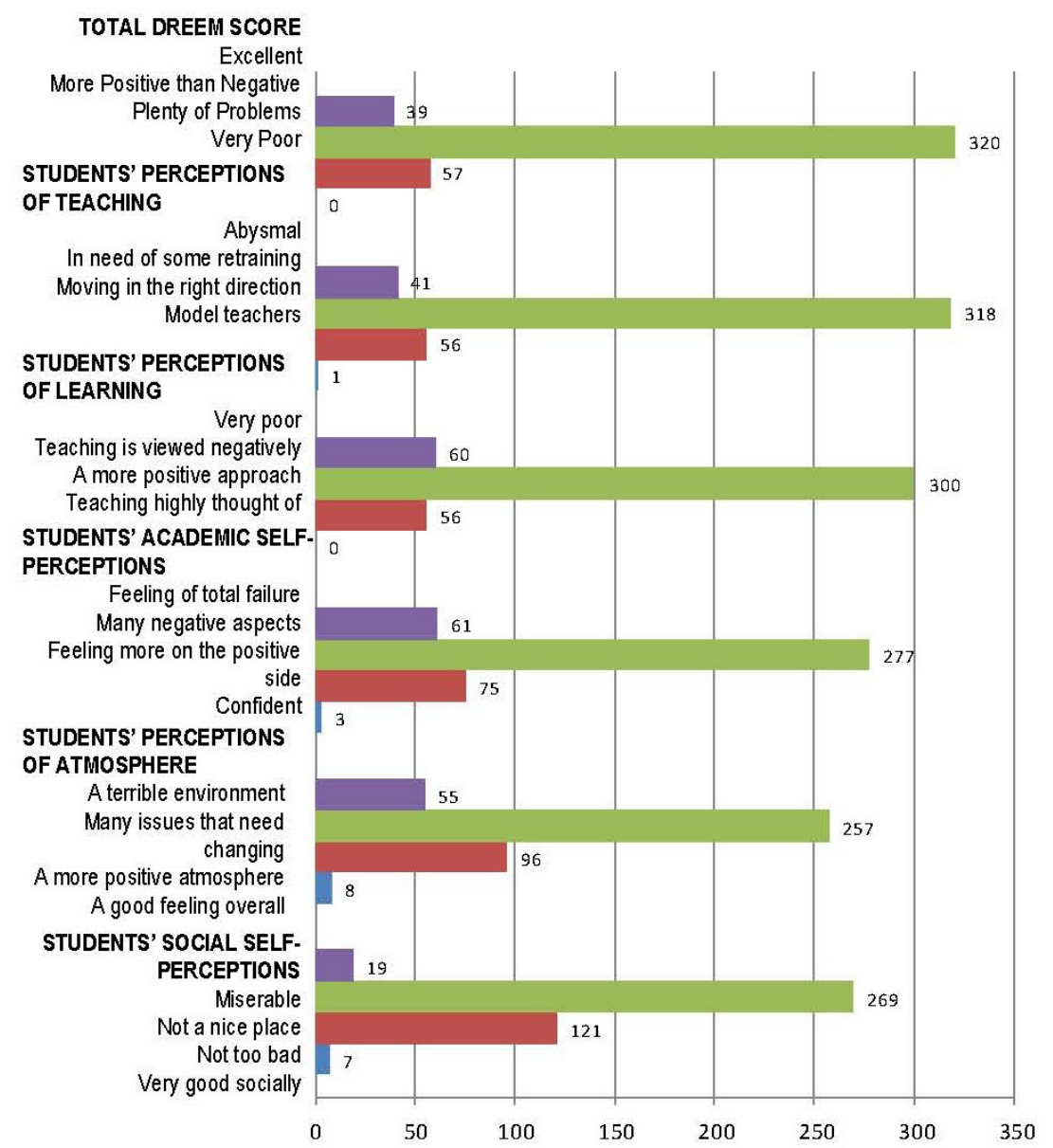

Figure 3: Description of The Five Domains of The Educational Environment As Reported by The Students of IMC during The Academic Calander Year 2015 (N=416). Notes: Mean difference is significant in

a 10 vs $11: p<0.005$; $^{b} 10$ vs $12: p<0.005$; $^{c} 10$ vs $11: p<0.002$; 10 vs 13 : $p<0.001$; ${ }^{e} 10$ vs $11: p<0.02$;

f 10 vs $14: p<0.05 ;{ }^{g} 10$ vs $11: p<0.001$ 


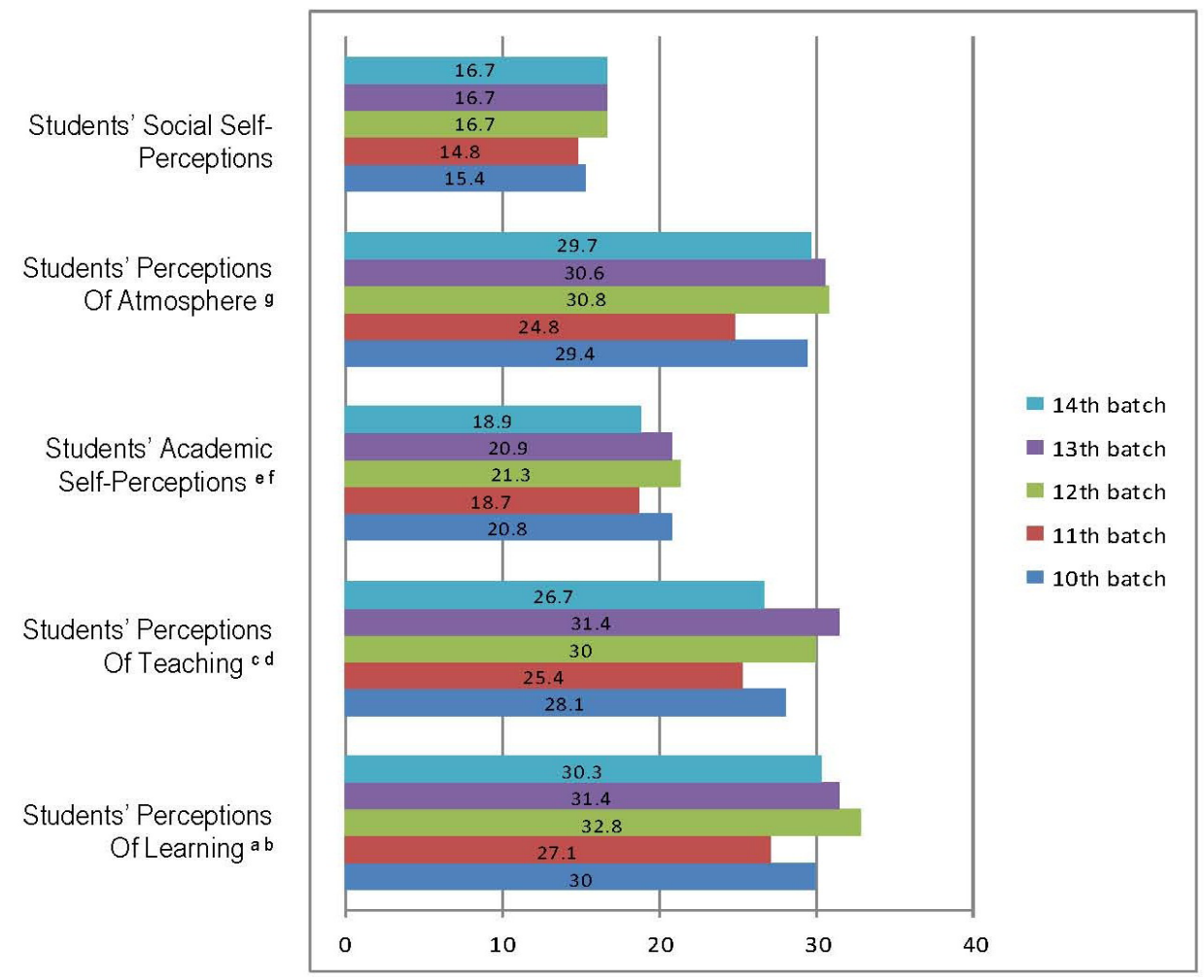

Figure 4: Average DREEM Score (Total And Sub-Scales) for comparison among Five Different Batches of Students of Ibrahim Medical College, Bangladesh in the Year 2015 ( $n=416)$.

Notes: Mean difference is significant in

a 10 vs $11: p<0.005 ;$; 10 vs $12: p<0.005 ;{ }^{c} 10$ vs $11: p<0.002 ;{ }^{d} 10$ vs $13: p<0.001 ;{ }^{e} 10$ vs $11: p<0.02$;

${ }^{f} 10$ vs $14: p<0.05 ;{ }^{g} 10$ vs $11: p<0.001$

were perceived fewer to develop interpersonal skill by female students. They also perceived cheating as a problem in the college, higher than the male. Although the environment was perceived as 'more positive than negative' by all batches, students of the $11^{\text {th }}$ batch (Term 8 ), in all five sub-scales, perceived the environment less favorable compared to other batches. When individual questions were compared, the $11^{\text {th }}$ batch reported the lowest satisfaction with 38 items. In three of the five subscales, students in the pre-or para-clinical years scored higher than the students in the clinical years (Table 5 and Figure 4).

\section{DISCUSSION}

The goals of the medical education curriculum are to produce graduates who have adequate knowledge, sufficient problem solving and manipulative skills, and the correct professional attitudes. The educational environment endeavors to nurture simultaneously two different orientations: a) task-orientation where the emphasis is on complex and diverse scientific tasks and b) social-emotional orientation where the emphasis is on the development of a caring person of sick people. ${ }^{12}$ The overall mean DREEM score for IMC students was 123.6 (95\% CI=121.59 to 125.61); which was within the range (101-150) that indicated a 'more positive than the negative' perception of the overall environment. Many institutions documented their mean score within this range. In a previous comparative study, the overall DREEM scores for medical schools in Sri Lanka, Nepal, Nigeria, Saudi Arabia, the UK (Birmingham), Chile, Kuwait, Sweden, Jamaica, Trinidad, and International Medical University and Universiti Sultan Zainal Abidin (Malaysia), University of British Columbia Medical School, were in this range (score 101-150). ${ }^{18,19}$ The only published previous study in Bangladesh revealed a lower overall mean score of 110 , but there is no significant difference in the current study as it is within the same range of 'more positive than negative. ${ }^{20}$ A few previous studies found higher overall mean DREEM scores, i.e. A study at Lund, University of Sweden recorded a high mean DREEM score of $145 .^{21}$ Fairy high mean DREEM scores were found in a study in the UK at different teaching hospital centers ${ }^{22}$ and in seven major medical sciences courses at Monash University in Australia, ${ }^{5}$ which were 139 and 137.3, respectively. Previous studies pointed out that students of innovative curricula have a tendency to show more satisfaction with their educational environments compared to students of traditional curricula, and higher DREEM scores tend to indicate more student-centered curricula. ${ }^{10,23}$ In Bangladesh, medical colleges cannot implement their own curricula, it is done centrally by BMDC, but senior teachers could guide juniors to make it more student-centered.

Medical education is very expensive, and academic failure is wasteful both to society and to the individual. Consequently, it has to be ensured that the environment is as conducive as possible to learn, thus reducing the risk of academic underachievement. ${ }^{18}$ In this study, the mean perceptions were expressed as percentages of maximum scores ranged between $57 \%-64 \%$ of the five domains. The mean score for the five sub-scales of the DREEM indicated that students' perceptions of learning were positive and that their perceptions of the teachers were moving in the right direction. Their academic self-perception was found to be more positive, their perception of the atmosphere was that 'a more positive atmosphere' and the students' social self-perception was 'not too bad.' Overall the mean DREEM scores were observed to be one step below 'perfect/ excellent,' which indicated that there was room for improvement in the aspects being measured by the DREEM at IMC. Hence, the 
authority could study the deficiencies that had been identified here and take measures to make the institution 'a center of excellence.'

Gender wise comparison showed no significant difference in overall and sub-domain mean scores between male and female students. The same observation was made by others; studies carried out in the Middle East, Trinidad, Sri Lanka, and India reported no significant sex differences between females and males. ${ }^{20}$ However, comparison of individual items revealed that male students perceived factors such as curriculum, structure, focus, and goals more positively than their female counterparts. This gender issue could potentially be addressed by further qualitative studies to identify reasons for female students lagging behind at selfconfidence level.

Perceptions of learning, the teacher, and atmosphere varied according to the students' year-level of enrollment. In the present study, pre-and para-clinical students scored higher in three domains compared to clinical students. These findings are in line with a study conducted on nursing students noted that the trend for reduced scores in the senior years and inferred that this trend could be due to the fact that students were mentally tired of being a student and looking forward to leaving student life. ${ }^{24}$ However, this difference did not follow a consistent pattern for every item or between $11^{\text {th }}$ and $10^{\text {th }}$ batch. So, further investigation of individual items, with particular emphasis on the $11^{\text {th }}$ batch, is required to help clarify these differences. Moreover, a study in a UK medical school inferred that change to a clinical hospital environment contributed to happier students. ${ }^{12}$ So the clinical phase could look closely to identify measures to improve the situation.

Finally, it is worth mentioning that increased stress and tiredness, lack of a good stress alleviating system, and an emphasis on factual learning were identified as the most significant problems perceived by students of the IMC. These problems are similar to those in some other universities and the impression that teachers are knowledgeable and well-prepared for their classes, but are too authoritarian, and strict has also been stated by other studies as-well. ${ }^{18}$ Another study revealed that the "educational institution should provide the student with a stress-free atmosphere for learning and developing his intellectual capabilities". ${ }^{25}$ Although a multi-center Bangladeshi study revealed that Bangladeshi medical students suffers from stress. ${ }^{26}$ But stress is not actually unique in Bangladesh also exist in many other countries. ${ }^{27-30}$ Improvement is required in many domains of the educational environment at this institution. Students of the $11^{\text {th }}$ Batch (eight semesters), particularly, perceived the environment negatively compared to other batches. The lowest scores were given to the support system, burdensome course content, and factual learning; thus, a curriculum that includes more problem-based learning and structured teaching with specific curricular objectives might improve the learning environment for students. ${ }^{26}$

Several problem areas were identified in the sub-scale of students' perception of atmosphere, indicating an atmosphere that is stressful and less enjoyable. In the students' social self-perception subscale, the study group agreed they had problems with the support systems available for those who get stressed. To improve their social perception issues, non-threatening environment, good social and academic support, pleasant accommodation, extra-curricular activities as well as mentoring of students by faculty, senior students and near-peers were suggested by previous studies. ${ }^{20}$ Assessments, which are an integral part of the educational process, need to be carefully planned and executed. ${ }^{18}$ They need to have clear objectives with provision for feedback so that remediation is available to those students who underperform and require additional support and monitoring.

\section{CONCLUSION}

As the learning environment affects students' motivation and achievement, it is important to get feedback from the students on how they are experiencing their learning environment on a regular basis. This study suggests that students enrolled in undergraduate courses at IMC generally hold positive perceptions of their course environment. Consequently, the contents of the curriculum, teachers' behavior with students', the atmosphere during teaching, and the social environment, support system during stress came out to be the main intervention areas for the further development of the educational environment of the college. Variations between year levels should be further investigated by qualitative assessments. The results obtained in this study can be used to plan for the use of available resources to achieve the institutional focus. These results can also serve as a baseline for a longitudinal quality assessment of students' perceptions of the college.

\section{ACKNOWLEDGEMENT}

Authors are much grateful to those students who participated in this study. Moreover, authors like to extend their heartfelt thanks to the Principal of Ibrahim Medical College, Bangladesh for his kind cooperation to conduct the study. As a final point, we expressed gratitude to Dr. Mohd Afandi bin Muhamad, Malaysia, for his comment and his notes.

\section{CONFLICT OF INTEREST}

Authors possess no financial or any other conflict of interest.

\section{ABBREVIATIONS USED}

DREEM: Dundee Ready Education Environment Measure'; UK: United Kingdom; IMC: Ibrahim Medical College; SPL: Students' Perceptions of Learning; SPT: Students' Perceptions of Teachers; SAP: Students' Academic Self-perceptions; SPA: Students' Perceptions of Academic Atmosphere; SSP: Students' Social Self-perceptions; BMDC: Bangladesh Medical and Dental Council.

\section{ABOUT AUTHORS}

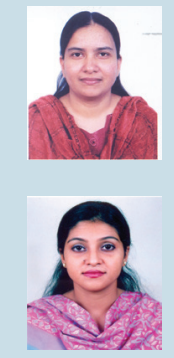

Dr. Masuda Mohsena: Is currently working as an Associate Professor in the Department of Community Medicine at Ibrahim Medical College. She is a medical graduate with Masters in Health Economics (DU, Bangladesh), Public Health (IUB) and Biological Anthropological Science (University of Cambridge, UK). In 2013, she has completed her PhD from University of Cambridge, UK.

Dr. Smita Debsarma: Is currently serving as Lecturer in the Department of Community Medicine at Ibrahim Medical College. Her dissertation topic in MPH was "Cirrhosis of Liver and Diabetes Mellitus" which has been published in Ibrahim Medical College Journal. Her area of interest is epidemiology of non-communicable disease and associated research. 


\section{REFERENCES}

1. Bhore SJ. A summary report of the workshop on the 'academic leadership training in the AIMST University, Malaysia'. J Young Pharm. 2013;5(2):67-9.

2. Kasilingam G, Ramalingam M, Chinnavan E. Assessment of learning domains to improve student's learning in higher education. J Young Pharm. 2014;6(1):27-33.

3. Tontus HÖ. Dreem; Dreams of the Educational Environment as Its Effect on Education Result of 11 Medical Faculties of Turkey, 2010.

4. General Medical Council. Tomorrow's Doctors: Outcomes and standards for undergraduate medical education. GMC, London. 2009. http://www.gmc-uk. org/Tomorrow_s_Doctors_1214.pdf_48905759.pdf

5. Brown T, Williams B, Lynch M. The Australian Dreem: Evaluating Student Perceptions of Academic Learning Environments within Eight Health Science Courses. Int J Med Edu. 2011;2:94-101.

6. Mayya S, Roff S. Students' Perceptions of Educational Environment: A Comparison of Academic Achievers and under-Achievers at Kasturba Medical College, India. Educ Health. 2004;17:280-91.

7. Helal RM, El-Masry R, El-Gilany A-H. Quality of Educational Environment among Egyptian Medical Students Using Dreem Questionnaire. World J Med Edu Res. 2013;3(1):6-14.

8. Ibrahim J. Review of Research in Learning Environment. JUMMC. 2008;11(1):711.

9. Bakhshi H, Bakhshialiabad MH, Hassanshahi G. Students' Perceptions of the Educational Environment in an Iranian Medical School, as Measured by the Dundee Ready Education Environment Measure. Bangladesh Med Res Counc Bull. 2014;40(1):36-41.

10. Roff S. The Dundee Ready Educational Environment Measure (Dreem)-a Generic Instrument for Measuring Students' Perceptions of Undergraduate Health Professions Curricula. Med Teach. 2005;27(4):322-25.

11. Roff S, McAleer S, Harden RM, Al-Qahtani M, Ahmed AU, Deza H, et al. Development and Validation of the Dundee Ready Education Environment Measure (Dreem). Med Teach. 1997:19(4):295-99.

12. Dunne F, McAleer S, Roff S. Assessment of the Undergraduate Medical Education Environment in a Large Uk Medical School. Health Education Journal. 2006;65(2):149-58.

13. Genn JM. Amee Medical Education Guide No. 23 (Part 2): Curriculum, Environment, Climate, Quality and Change in Medical Education-a Unifying Perspective. Med Teach. 2001;23(5):445-54

14. Pai PG, Menezes V, Srikanth, Subramanian AM, Shenoy JP. Medical Students' Perception of Their Educational Environment. J Clin Diag Res. 2014;8(1):103-7.

15. Roff S, McAleer S, Ifere OS, Bhattacharya S. A Global Diagnostic Tool for Measuring Educational Environment: Comparing Nigeria and Nepal. Med Teach. $2001 ; 23(4): 378-82$

16. Whittle SR, Whelan B, Murdoch-Eaton DG. Dreem and Beyond; Studies of the Educational Environment as a Means for Its Enhancement. Educ Health. 2007;20(1):7.

17. McAleer S, Roff S. A Practical Guide to Using the Dundee Ready Education
Environment Measure (Dreem) In: Genn J, editor. Amee Medical Education Guide No23 Curriculum, Environment, Climate, Quality and Change in Medical Education; a Unifying Perspective. Dundee (UK): Association of Medical Education in Europe. 29-33, 2001.

18. Bakhshialiabad H, Bakhshi M, Hassanshahi G. Students' Perceptions of the Academic Learning Environment in Seven Medical Sciences Courses Based on Dreem. Adv Med Educ Prac. 2015:6:195-203.

19. Rahman NIA, Aziz AA, Zulkifli Z, Haj MA, Nasir FHBM, Pergalathan S, et al. Perceptions of students in different phases of medical education of the educational environment: Universiti Sultan Zainal Abidin. Adv Med Educ Pract. 2015;6:211-22.

20. Nahar N, Talukder MHK, Khan MTH, Mohammad S, Nargis T. Students' Perception of Educational Environment of Medical Colleges in Bangladesh. BSMMU J. 2012;3(2):97-102.

21. Edgren G, Haffling AC, Jakobsson U, McAleer S, Danielsen N. Comparing the Educational Environment (as Measured by Dreem) at Two Different Stages of Curriculum Reform. Med Teach. 2010;32(6):e233-238.

22. Varma R, Tiyagi E, Gupta JK. Determining the Quality of Educational Climate across Multiple Undergraduate Teaching Sites Using the Dreem Inventory. BMC Medical Education. 2005;5(1):8.

23. Roff S, McAleer S. What Is Educational Climate? MedTeach. 2001;23(4):333-34.

24. Mohd Said N, Rogayah J, Hafizah A. A Study of Learning Environments in the Kulliyyah (Faculty) of Nursing, International Islamic University Malaysia. Malays J Med Sci. 2009;16(4):15-24.

25. Jishnu V, Gilhotra RM, Mishra DN. Pharmacy Education in India: Strategies for a Better Future. J Young Pharm. 2011;3(4):334-42.

26. Eva EO, Islam MZ, MosaddekAS, Rahman MF, Rozario RJ, Iftekhar AF, et al. Prevalence of stress among medical students: a comparative study between public and private medical schools in Bangladesh. BMC Res Notes. 2015;8(1):327.

27. Rahman NIA, Ismail S, Ali RM, Alattraqchi AG, Dali WPEW, Umar BU, et al. Stress among first batch of MBBS students of Faculty of Medicine and Health Sciences, Universiti Sultan Zainal Abidin, Malaysia: when final professional examination is knocking the door. Int Med J. 2015;22(4):1-6.

28. Rahman NIA, Ismail S, Seman TNABT, Rosli NFAB, Jusoh SABM, Dali WPEW, et al. Stress among preclinical medical students of Universiti Sultan Zainal Abidin. J App Pharm Sci. 2013;3(11):76-81.

29. Salam A, Yousuf R, Bakar SMA, Haque M. Stress among Medical Students in Malaysia: A Systematic Review of Literatures. Int Med J. 2013;20(6):649-655.

30. Oku AO, Owoaje ET, Oku OO, Ikpeme BM. Prevalence of stress, stressors and coping strategies among medical students in a Nigerian medical school. Afr J Med Health Sci. 2015;14(1):29-34.

31. Kohli V, Dhaliwal U. Medical Students' Perception of the Educational Environment in a Medical College in India: A Cross-Sectional Study Using the Dundee Ready Education Environment Questionnaire. J Educ Eval Health Prof. 2013;10:5. 